\title{
Percolation Mathematical Model for Stepped Horizontal Well in Multi- layer Fault Block Reservoir
}

\author{
Liu Hong ${ }^{1, *}$, Pang Jin ${ }^{1}$, Chang Xuejun ${ }^{2}$, Yu Xinan ${ }^{1}$ and Zhang $\mathrm{Xu}^{1}$ \\ ${ }^{I}$ Chongqing University of Science and Technology, Chongqing 401331, China \\ ${ }^{2}$ Jidong Oilfield Company of Petrochina, Tangshan 063299, China
}

\begin{abstract}
The percolation mechanism and regularity for stepped horizontal well in multi-layer complex fault block reservoir are complex. A percolation mathematical model based on unsteady flow mathematical model is built up in this paper. In the model, the reservoir couples with one horizontal well in sealed reservoir which perforates through mutually unconnected formation. Laplace transform, Stehfest inversion and Conjugate gradient are used to solve the model. The pressure distribution results of different time and production distribution results of different well section can be obtained. The results of pressure drop and pressure drop derivative calculated by this model are close to the results calculated by the Saphir software, and the agreement rate is $99 \%$, which proves the model is of great reliability. Compared with Saphir software, the capacity of horizontal section through multiple sand at the same time can be calculated, which is the advantage of this model. It is not suitable for heterogeneous reservoir and the reservoir with supply boundary, which is the limitation. A two-layer block fault reservoir has been used to carry out the field study through the model, simplifying the irregular shape of reservoir for rectangular reservoir at first. Then a double-stage horizontal well is used to pass through the upper layer and the lower layer orderly in this reservoir, the simulation calculation of the well can use the double-stage horizontal well model, and the model can calculate the average pressure drop and pressure drop derivative of various production phases in the bottom hole accurately. The reservoir flow stage and the flow time in different periods can be judged through pressure drop and pressure drop derivative in the bottom hole, which can also calculate the distribution of production along the horizontal section in different periods at the same time. It can provide theoretical foundation of reservoir research engineering and production engineering design for reservoir development with stepped horizontal well in multilayer complex fault block reservoir.
\end{abstract}

Keywords: Complex fault block, Horizontal well, Multilayer reservoir, Percolation Model, Stepped well.

\section{INTRODUCTION}

High-efficient development of oil and gas reservoir with complex fault block, low well control and multilayer are the technological problems that the oilfield is facing in our country [1]. Directional well, horizontal well, multilateral well, cluster well and stepped well have always been applied in such reservoirs domestically and in other countries over the world. The stepped horizontal well which is adopted in recent years, becomes a new type, and the well structure is complex [2-4]. The percolation mechanism on such wells with complex well configuration mainly refers to the study of horizontal well and vertical well. In fact, the studies need to be further improved [5-10].

A percolation model is established with one or more wells in the bounded reservoir based on single-phase flow pressure gradient model built by Ouyang [11, 12], coupled with flow model in wellbore and reservoir for cluster well inflow performance in infinite reservoir built by Ouyang [13], and source function on bounded reservoir flow equation built by Gringarten and Ramey [14]. Each well may

*Address correspondence to this author at the Chongqing University of Science and Technology, Chongqing 401331, China; Tel: +86 2365022798 ; Fax: +86 23 65022798; E-mail: liubrett@vip.sina.com have several multilateral wells, and each multilateral well may have vertical well section, inclined well section and horizontal well section. Each well is located in one bounded reservoir or perforates through a reservoir which is not mutually connected. The solution of the model contains many rapid linear algebraic calculation methods, such as Laplace changing numerical algorithm by Zhao and Thompson [15], numerical Laplace inversion algorithm by Stehfest [16], and Conjugate gradient methods [17]. Furthermore, the model is applied in pressure and production calculation of complex wells in fault block oil reservoir.

\section{RESERVOIR FLOW EQUATION}

It is supposed that there are one or more oil wells or water wells in the rectangular reservoirs, which are interconnected or disconnected. Each well may have vertical well section, inclined well section and horizontal well section. The restricted conditions are as follows:

(1) Each layer has the same or similar initial flow potential energy before it is developed.

(2) Each layer is in the same pressure system after perforation, but pressure transmission of non-communicating layers is connected with wellbore. 
(3) Suppose that oil layers are disconnected, and each layer is homogenous and anisotropic. But each layer has the various characteristics of porosity, permeability and total compressibility.

(4) Each layer has a different coordinate system in order to deal with anisotropic feature of oil layers.

(5) Each oil layer has a closed boundary.

(6) Properties of oil layers do not change with pressure.

(7) Suppose that formation fluid is single phase and it is with weak compressibility. The fluid of each layer may have diverse compressibility and viscosity, but they are constant.

Thus, the flow equation in the $j^{\text {th }}$ layer is:

$K x_{j} \frac{\partial^{2} \varphi}{\partial x_{j}^{2}}+K y_{j} \frac{\partial^{2} \varphi}{\partial y_{j}^{2}}+K z_{j} \frac{\partial^{2} \varphi}{\partial z_{j}^{2}}=\phi_{j} \mu_{j} C_{t j} \frac{\partial \varphi}{\partial t}$

where the compressibility is:

$C_{t j}=-\frac{1}{B_{j}} \frac{d B_{j}}{d P_{j}}+\frac{1}{\phi_{j}} \frac{d \phi_{j}}{d P_{j}}$

Usually we assume that the positive direction of $\mathrm{Zj}$ is vertically up. If we suppose the fluid density $\rho$ is a constant, the potential energy of formation fluid $\varphi$ can be calculated by:

$$
\varphi=P+\int_{0}^{z} \frac{g}{g_{c}} \rho d z=P+\frac{g}{g_{c}} \rho z
$$

In order to make the result of equation (1) universal, we should make it dimensionless.

The dimensionless fluid energy is defined as:

$\varphi_{D j}=\frac{\varphi_{\mathrm{i}}-\varphi\left(x_{j}, y_{j}, z_{j}, t\right)}{\varphi_{\mathrm{i}}}$

The dimensionless time is defined as:

$$
t_{D j}=\frac{K t}{\phi_{j} \mu_{j} C_{t j} L^{2}}
$$

The dimensionless coordinate is defined as:

$$
\begin{aligned}
& x_{D j}=\frac{x_{j}}{L} \sqrt{\frac{K}{K x_{j}}} \\
& y_{D j}=\frac{y_{j}}{L} \sqrt{\frac{K}{K y_{j}}} \\
& z_{D j}=\frac{z_{j}}{L} \sqrt{\frac{K}{K z_{j}}}
\end{aligned}
$$

Putting the dimensionless variables into equation (1), a dimensionless flow equation can be gotten: $\frac{\partial^{2} \varphi_{D j}}{\partial x_{D j}{ }^{2}}+\frac{\partial^{2} \varphi_{D j}}{\partial y_{D j}{ }^{2}}+\frac{\partial^{2} \varphi_{D j}}{\partial z_{D j}{ }^{2}}=\frac{\partial \varphi_{D j}}{\partial t_{D j}}$

Equation (9) shows that all the aeolotropism problems can be solved by translated into isotropy problems.

Initial conditions of the system:

$\varphi_{D j}=\varphi_{D i}$

Boundary conditions of the system :

$\frac{\partial \varphi_{D j}}{\partial x_{D j}}=\frac{\partial \varphi_{D j}}{\partial y_{D j}}=\frac{\partial \varphi_{D j}}{\partial z_{D j}}=0$

Equations (10) and (11) can be solved by the originated function, which is generated from the Green function.

\section{WELLBORE FLOW EQUATION}

The flow pressure gradient of wellbore could be defined by the equation:

$\frac{d P}{d l}=-\frac{4 \tau_{w}}{D}-\rho \frac{g}{g_{c}} \sin \theta-\frac{z}{g_{c} A} \rho V q_{1}$

$\tau_{\mathrm{w}}$ is defined by:

$\tau_{w}=\frac{1}{7 g_{c}} f \rho V|V|$

where $\mathrm{f}$ is wall friction factor.

As to production well:

$f=\frac{16}{N_{\mathrm{Re}}}\left(1+0.04304 N_{\mathrm{Rew}}^{0.6142}\right)$

As to injection well:

$f=\frac{16}{N_{\text {Re }}}\left[1-0.0625 \frac{\left(-N_{\text {Rew }}\right)^{1.3056}}{\left(N_{\text {Rew }}+4.626\right)^{0.2724}}\right]$

And equation (12) can be expressed in the gradient form of fluid potential energy:

$\frac{d \varphi}{d l}=-\frac{4 \tau_{w}}{D}-\frac{z}{g_{c} A} \rho V q_{1}=\left(\frac{d P}{d l}\right)_{f}+\left(\frac{d P}{d l}\right)_{a}$

\section{MODEL SOLUTION}

Use a well through two disconnected reservoirs as an example to establish the equation and solve it. It is of high degree similarity to the case of multi-layers and multi-wells. The model is illustrated as in Fig. (1).

Assuming that the dimensionless potential energy of point $1 \mathrm{~A}$ is $\varphi_{\mathrm{D} 1 \mathrm{~A}(\mathrm{t})}$, the dimensionless production is $Q_{D}$, at any time $t$, the equations can be gotten as follows: 


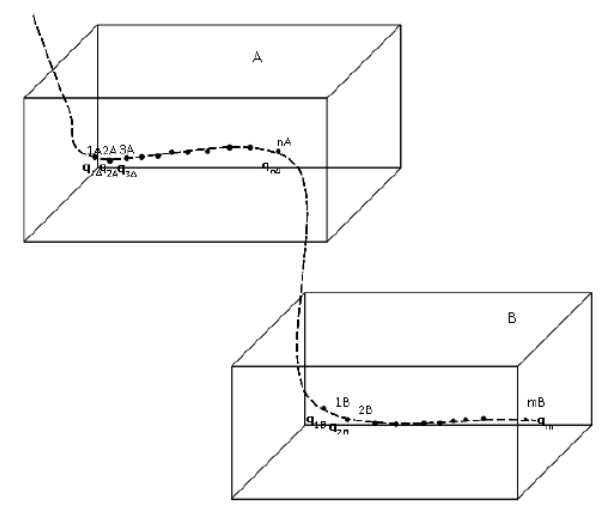

Fig. (1). Model illustration.

$$
\begin{aligned}
\sum_{i=1}^{n} q_{D i A}(t)+\sum_{j=1}^{m} q_{D j B}(t)=Q_{D} \\
\varphi_{D 2 A}(t)=\varphi_{D 1 A}(t)+\Delta \varphi_{D f 12}(t)+\Delta \varphi_{D a 12}(t) \\
=\sum_{i=1}^{n} \int_{0}^{t} q_{D i A}(\tau) S_{2 i A}(t-\tau) d \tau+ \\
\sum_{j=1}^{m} \int_{0}^{t} q_{D j B}(\tau) S_{2 j B}(t-\tau) d \tau \\
\varphi_{D(m+n) A}(t)=\varphi_{D 1 A}(t)+\Delta \varphi_{D f 1(m+n)}(t)+\Delta \varphi_{D a 1(m+n)}(t) \\
=\sum_{i=1}^{n} \int_{0}^{t} q_{D i A}(\tau) S_{(m+n) i A}(t-\tau) d \tau+ \\
\sum_{j=1}^{m} \int_{0}^{t} q_{D j B}(\tau) S_{(m+n) j B}(t-\tau) d \tau
\end{aligned}
$$

$m+n+1$ equations are concluded in equation (17) and equation (18) through which $m+n+1$ unknown counts can be solved. Assuming that $\mathrm{Q}_{\mathrm{D}}$ is known, $m+n+1$ unknown counts are $\varphi_{D 1 A}, \mathrm{q}_{1 A}, \mathrm{q}_{2 A}, \ldots . . \mathrm{q}_{\mathrm{n} A}, \mathrm{q}_{1 B}, \mathrm{q}_{1 B}, \ldots . . \mathrm{q}_{m B}$. All the items in the originated function can be calculated by the Newman multiplication principle. The equation (17) and equation (18) need to be solved by the Iterative method. And the changing items of the dimensionless potential energy are the functions of production. The changing items could be defined by the equation below:

$$
\begin{aligned}
& \Delta \varphi_{D f 12}(t)=-\frac{1}{\varphi_{i}}\left(\frac{4}{D} \Delta L_{12} \tau_{w 12}\right) \\
& \tau_{w 12}=\frac{1}{2} f \rho \mathrm{V}_{12}^{2} \\
& \Delta \varphi_{D \mathrm{a} 12}(t)=-\frac{1}{\varphi_{i}}\left(\frac{2}{\mathrm{~A}} \rho \mathrm{V}_{12} q_{12}\right)
\end{aligned}
$$

where $\varphi_{I f f}(t)$ represents the potential energy difference caused by the wellbore friction between points $1 \mathrm{~A}$ and $2 \mathrm{~A}$ at any time. Where $\varphi_{\mathrm{DS}_{\mathrm{A}}}(t)$ represents the potential energy difference caused by the acceleration between points $1 A$ and $2 A$ at any time. $\Delta L_{12}$ represents the length from point $1 A$ to point $2 A$. $V_{12}$ represents the axial velocity of flow. $q_{12}$ is the average flow rate of the well wall, parameter $f$ will be determined by equation (14) and equation (15). Thus, the potential energy difference of other well sections can be solved by the similar method.

Equation (17) and equation (18) can be solved by Laplace transform, and it can be evidenced from the convolution of Laplace transform:

$$
\begin{aligned}
& \sum_{i=1}^{n} \bar{q}_{D i A}(s)+\sum_{j=1}^{m} \bar{q}_{D j B}(s)=\frac{Q_{D}}{s} \\
& \bar{\varphi}_{D 1 A}(s)=\sum_{i=1}^{n} \bar{q}_{D i A}(s) \bar{S}_{1 i A}(s)+\sum_{j=1}^{m} \bar{q}_{D j B}(s) \bar{S}_{1 j B}(s) \\
& \bar{\varphi}_{D 2 A}(s)=\bar{\varphi}_{D 1 A}(s)+\Delta \bar{\varphi}_{D f 12}(s)+\Delta \bar{\varphi}_{D a 12}(s) \\
& =\sum_{i=1}^{n} \bar{q}_{D i A}(s) \bar{S}_{2 i A}(s)+\sum_{j=1}^{m} \bar{q}_{D j B}(s) \bar{S}_{2 j B}(s) \\
& \bar{\varphi}_{D(m+n) A}(s)=\bar{\varphi}_{D 1 A}(s)+\Delta \bar{\varphi}_{D f 1(m+n)}(s)+\Delta \bar{\varphi}_{D a 1(m+n)}(s) \\
& =\sum_{i=1}^{n}-\bar{q}_{D i A}(s) \bar{S}_{(m+n) i A}(s)+\sum_{j=1}^{m} \bar{q}_{D j B}(s) \bar{S}_{(m+n) j B}(s)
\end{aligned}
$$

Equation (20) and equation (21) are obtained through equation (17) and equation (18) respectively on Laplace space. They can be calculated from Iterative method and translated into the actual space by Stehfest method.

\section{MODEL VALIDATION}

In order to validate the effectiveness of the model, the model is used to calculate the drop of pressure of horizontal well and the drop of pressure derivate in one-sand body. The final results are compared with the Saphir software calculation results.

The verified parameters of the model are: sand body length: $x_{\mathrm{e}}=2.3 \mathrm{~km}$, width: $\mathrm{y}_{\mathrm{e}}=2.0 \mathrm{~km}$, height: $\mathrm{z}_{\mathrm{e}}=10 \mathrm{~m}$, flow internal diameter: $0.1 \mathrm{~m}, \mathrm{k}: 40 \mathrm{mD}$, formation porosity: 0.2 , formation compression factor: $5 \times 10^{-4} / \mathrm{MPa}$, oil viscosity: $1 \mathrm{mPa} . \mathrm{s}$, daily productivity: $100 \mathrm{~m}^{3} / \mathrm{d}$, horizontal well location: $\mathrm{x}=1-1.3 \mathrm{~km}, \mathrm{y}=1 \mathrm{~km}, \mathrm{z}=5 \mathrm{~m}$.

According to the Fig. (2), the calculation of pressure derivative shows that the reservoir flow is unsteady flow at the beginning of the well production from 0.02 days to 10 days. Ten days later, the flow reaches the boundary, and the reservoir flow is the quasisteady state flow. For both pressure and pressure derivative, the results calculated by this model are almost consistent with the results calculated by Saphir software; the deviation lies only in the early part of the flow, which means the production time is less than 0.1 days. The pressure derivative results calculated by this model are a little greater than simulation calculation results 


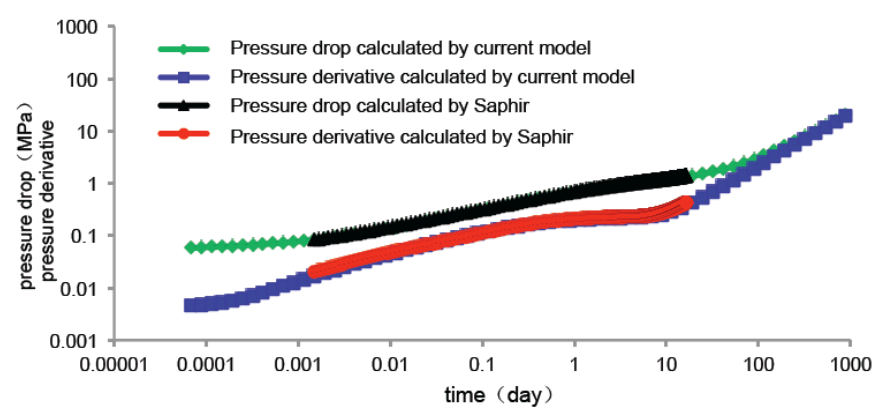

Fig. (2). Calculated pressure drop and pressure drop derivative using current model contrast with applying Saphir calculation (horizontal well).

Table 1. Parametric table listing the reservoir properties.

\begin{tabular}{|c|c|c|c|c|c|c|c|c|c|c|}
\hline Sand body & $\begin{array}{c}\text { Oil area } \\
\mathbf{K m}^{2}\end{array}$ & $\begin{array}{c}\text { Effective } \\
\text { sickness } \\
\text { m }\end{array}$ & $\begin{array}{c}\text { Porosity } \\
\%\end{array}$ & $\begin{array}{l}\text { Permeabil- } \\
\text { ity } 10^{-3} \mu \mathrm{m}^{2}\end{array}$ & $\begin{array}{l}\text { Viscosity } \\
\text { mPa.s }\end{array}$ & $\begin{array}{c}\text { Length } \\
\text { m }\end{array}$ & $\begin{array}{c}\text { Width } \\
\text { m }\end{array}$ & $\begin{array}{l}\text { Dimension- } \\
\text { less length } f\end{array}$ & $\begin{array}{l}\text { Dimension- } \\
\text { less width } \mathrm{f}\end{array}$ & $\begin{array}{l}\text { Dimension- } \\
\text { less thick- } \\
\text { ness } f\end{array}$ \\
\hline 46 up & 2.60 & 18.5 & 18.75 & 74 & 2 & 2000 & 1300 & 1 & 0.65 & 0.00923 \\
\hline 48 up & 3.12 & 12.5 & 20.51 & 92 & 2 & 3180 & 981 & 1.59 & 0.49 & 0.00625 \\
\hline
\end{tabular}
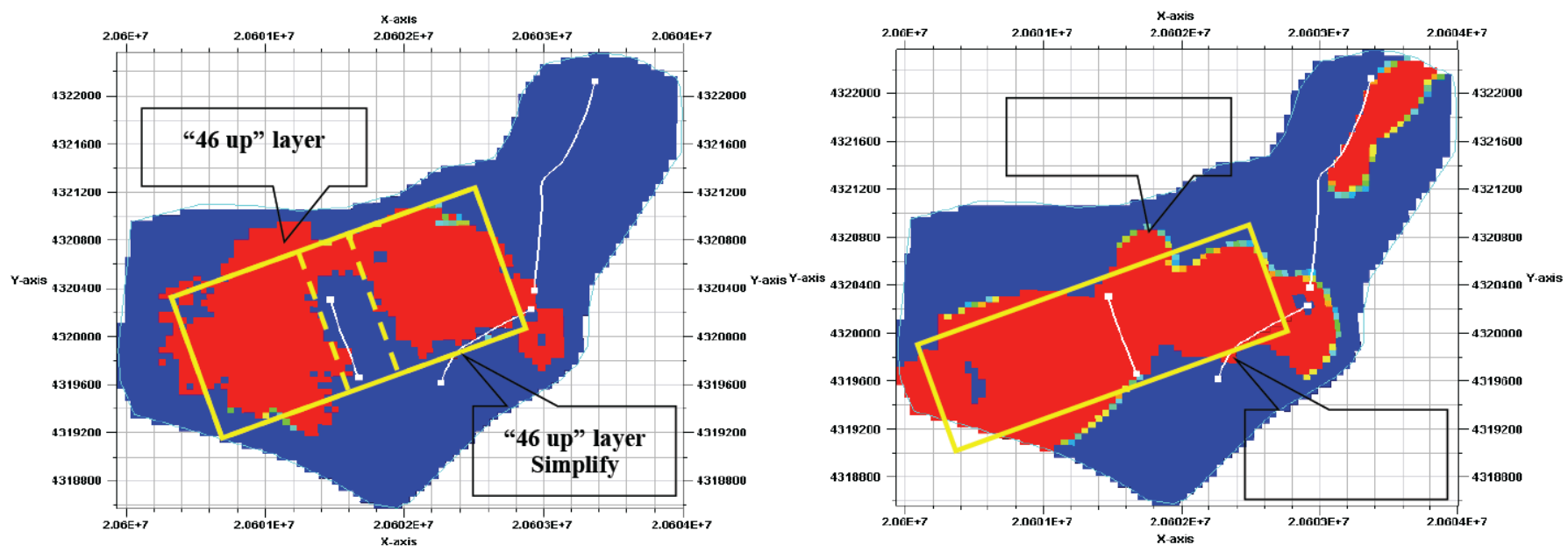

Fig. (3). Oil-bearing area diagram of the reservoir (the left is“46 up”, the right is“48 up").

by using Saphir software, but its deviation is less than $1 \%$. The whole self-agreement of results calculated by the model and by the software reaches $99 \%$, which shows that the results calculated by the model are reliable, and hence the model can be extended to calculate capacity in reservoir that contains more than one-sand body.

\section{PRACTICAL EXAMPLE OF CALCULATION ANALYSIS}

A fault block oil reservoir is used for a typical example. The reservoir consists of two-sand bodies ("46 up" and "48 up"). Their properties are shown in Table 1 and the oilbearing area of sand body is shown in Fig. (3). The reservoir is controlled by oil rate target at $100 \mathrm{~m}^{3}$ per day, so the drop of pressure, the drop of pressure derivative, and production of a well through the two-sand bodies can be calculated at the same time by the model as is mentioned in this paper.

According to the geometrical shape of oil-bearing area, the two-sand bodies are simplified. We assume that a horizontal well penetrates the left sand body of " 46 up" in the middle of left side, goes out at right side, then goes down to "48 up", and passes through it at right side (Fig. 4). The average dimensionless pressure drop and the dimensionless pressure drop derivative at the bottom of the wellbore in different times are as shown in Fig. (5). The production distribution at different levels of time and different horizontal sections is as shown in Fig. (6).

Because the simulation in this well is under the constant production rate condition, the production in the whole process is certain. However, because the spread range of oil well in different periods is different, the initial spread range is small, but the spread range is large at the end of the period, until the pressure wave blocks all the boundaries. Therefore, the flow of the oil wells can be divided into different stages according to the bottom hole pressure drop and pressure drop derivative in different periods. 

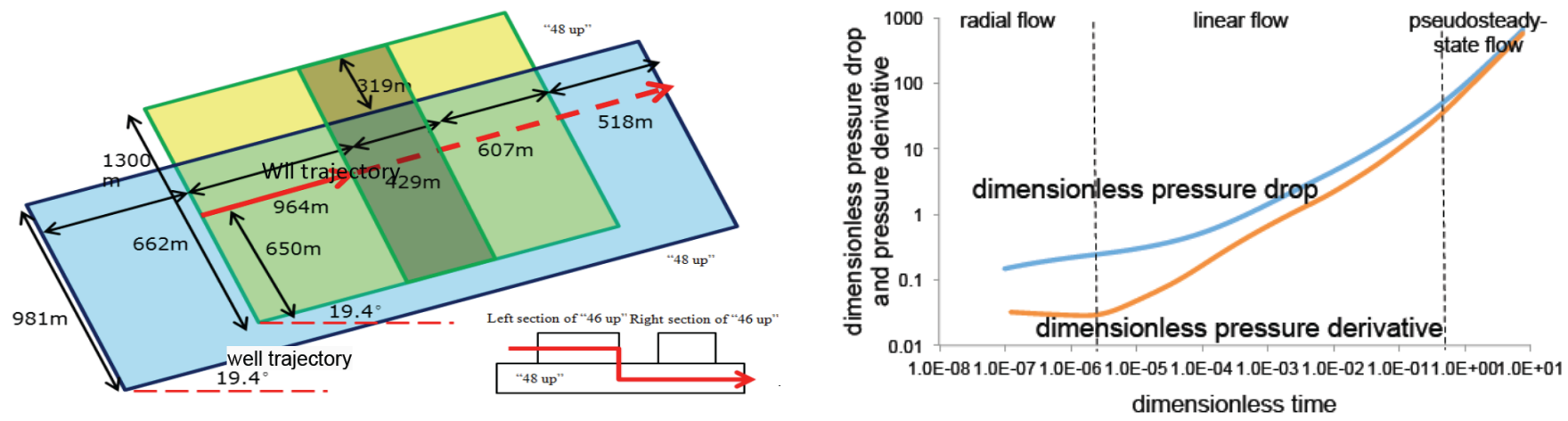

Fig. (4). Simplified graph of reservoir case.

Fig. (5). Horizontal well pressure and pressure derivative.

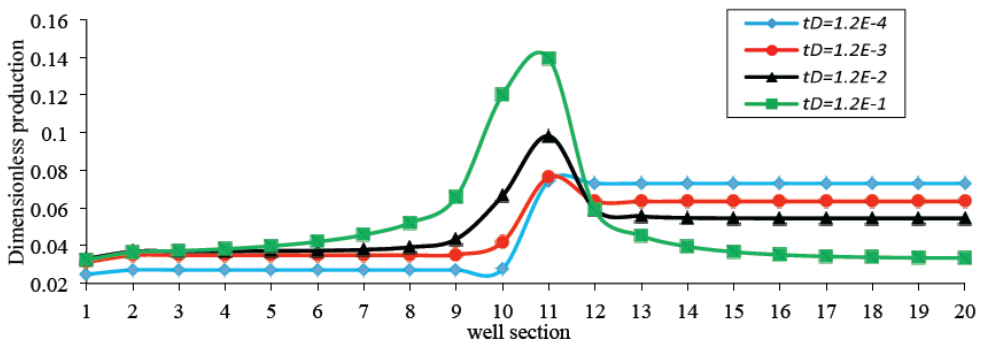

Fig. (6). Production in different well sections at different time of horizontal well.

Bottom hole pressure drop trend consists of three stages: radial flow stage, linear flow stage and pseudo steady-state flow stage. The pressure drop is not obvious at radial flow stage. When pressure drop delivers to upper and lower boundary of the formation, the linear flow stage starts and pressure drop increases significantly. The pseudo steadystate flow stage starts when pressure drop delivers to horizontal boundary of the formation. However, pressure drop derivative increases linearly along with time.

The productivity can be judged in turn according to the size of the pressure drop; that is, when the oil wells are under the same production, the smaller the bottom hole pressure drop, the greater the production capacity is, the greater the bottom hole pressure drop, and the smaller the production capacity is.

In the process of under the condition of constant production rate in the oil well, although the total productions remain unchanged, the pressure in different well sections of horizontal wellbore in different periods is not the same, which contributes differently to the total production of horizontal well in different production periods. This is because the spread range of puessure wave is different in different periods.

Owing to the horizontal well section of " 46 up" nearly penetrates left side of " 46 up", the yield distribution of each section is basically consistent. Since the sections penetrated in "48 up" are not from the same end, the first nodal point has a high yield whereas the other nodal points' outputs basically remain unchanged. Wellbore initial output of " 46 up" is less than that of "48 up", because the length of the horizontal well section that is penetrated in " 46 up" is less than that of " 48 up". As the time goes by, after the fluid reaches the boundary, the volume size of the sand bodies becomes the leading factor that influences the yield. The wellbore output of " 46 up" is slightly higher than that of " 48 up".

\section{DISCUSSION}

on the basis of the simplified multi-layer fault block reservoir, the production pressure drop, pressure drop of the derivative and well production distribution under the constant production rate condition in multi-layer fault block reservoir can be accurately calculated by the model proposed in this study. Furthermore, the flow state in reservoir and oil well productivity can be judged in different periods, which provides theoretical support for oil reservoir capacity calculation and well location optimization of selecting well in multi-layer fault block reservoir, making up for the inadequacy of the existing business well test software. But this model also has certain limitations and therefore, it needs indepth study in the future. The study mainly includes: (1) A model is put forward and set up for closed fault block oil reservoir; in order to solve the oil reservoir with supply boundary, the boundary conditions are required to set up again; (2) The proposed model however, is not suitable to calculate the intraformational heterogeneity, interlayer channeling and other complex flow conditions in the reservoir: (3) It is used without considering wellbore storage effect, so the flow pressure drop and pressure drop of the derivative calculated by the model can appear with a larger deviation at the beginning of the flow period.

\section{CONCLUSION}

The results show that the advancement of this model mainly reflects in the following four aspects:

(1) The model has used the unsteady state flow mathematical model, which is more close to the actual flow condition to describe the flow reservoir fluid better.

(2) The transient flow mathematical model is established under the reservoir and the complicated wellbore coupling conditions. The fluid friction and momentum change are considered in the wellbore flow model. 
(3) Each well can contain many vertical, slope and horizontal well sections in the model. Therefore, the case of one well crossing over many disconnected formations is allowed, which complies with the development of practical fault block reservoirs.

(4) The model adopts rapid linear algebraic calculation methods such as source function for flow equation of bounded reservoir by Gringarten and Ramey, numerical algorithm for Laplace transform by Zhao and Thompson, numerical algorithm for Laplace inversion by Stehfest and Conjugate gradient methods for equation solving. It is trustworthy both in computational accuracy and speed.

\section{SYMBOL INSTRUCTIONS}

$\Phi$-flow potential energy, f

$x, y, z$-coordinate

$\mu$-viscosity, mPa.s

$K$-permeability, $\mathrm{mD}$

$B$-volume factor, $\mathrm{f}$

$P$-formation pressure, $\mathrm{MPa}$

$L$-reference length, $\mathrm{m}$

$q_{1}$ - flow capacity in unit wellbore or flow capacity in unit wellbore, $\mathrm{m}^{3} / \mathrm{d}$

$V$-axial flow rate of corresponding segment (q1and $\mathrm{V}$ take the positive value in the case of production well, take the negative one in the case of injection well), $\mathrm{m} / \mathrm{s}$

$D$-shaft diameter, $\mathrm{m}$

$g$-acceleration of gravity, $\mathrm{m} / \mathrm{s}^{2}$

$g_{c}-$ conversion factor of gravity acceleration

$\rho$-wellbore fluid density, $\mathrm{Kg} / \mathrm{m}^{3}$

$t$-time, $\mathrm{d}$

$C$-compressibility, $1 / \mathrm{MPa}$

$\phi$-porosity, $\mathrm{f}$

$\theta$-angle of the wellbore and horizontal direction, ${ }^{\circ}$

$\tau_{w}$-wellbore friction stresses, MPa

$f$-wall friction coefficient

$N_{R e}$-Reynolds number

subscript $j$ - number of layer

subscript $D$-dimensionless quantity

subscript $A, B$ - sand body symbol

subscript $m, n$-localization in the horizontal well

\section{CONFLICT OF INTEREST}

The authors confirm that this article content has no conflict of interest.

\section{ACKNOWLEDGEMENTS}

This project was supported by the National Natural Science Foundation of China (Grant No. 51174245, 51374265).

\section{REFERENCES}

[1] R. Wan, C. Xie, J. Zheng, Horizontal Wells Technology. Beijng: Petroleum Industry Press, 1995

[2] W. Haijing, X. Shifeng, G. Cunfa, and X. Tong, "Inflow performance for highly deviated wells in anisotropic reservoirs", Petroleum Exploration and Development, vol. 39, no. 2, pp. 222-227, 2012.

[3] B.D. Poe, and A. Erkal, "Transient behavior of horizontal wells with inflow control devices for inflow profile modification". In: International Oil and Gas Conference and Exhibition in China", Beijing, China; Society of Petroleum Engineers, 2010.

[4] M. Prats, and R. Raghavan, "Finite horizontal well in a uniformthickness reservoir crossing a natural fracture normally", SPE Journal, vol. 18, no. 5, pp. 982-992, 2013.

[5] M. Li, G. Sun, and Z. Liu "Cluster horizontal wells group applied research in petroleum exploration and development of complex fault block reservoir development", Petroleum Exploration and Development, no. 6, 2002.

[6] R. Lan, J. Zhao, Y. Hu, and J. Sun, "Block reservoir seepage characteristic stepped horizontal wells", Oil Journal, no. 1, 2011.

[7] M. Li "Complex structure wells in Liaohe oil region", Foreign Energy, no.06, 2009

[8] S. Jabbar, and D. Tiab, "Finite horizontal well crossing a natural fracture normally", SPE Journal, vol. 17, no. 2, pp. 555-567, 2012.

[9] C. Chen, and R. Raghavan, "On some characteristic features of fractured-horizontal wells and conclusions drawn thereof", $S P E$ Reservoir Evaluation and Engineering, vol. 16, no. 1, pp. 19-28, 2013.

[10] J. Hagoort, "Semisteady-state productivity of a well in a rectangular reservoir producing at constant rate or constant pressure", $S P E$ Reservoir Evaluation and Engineering, , vol. 14, no. 6, pp. 677686, 2011.

[11] L.B. Ouyang, L.K. Thomas, C.E. Evans, and K. Aziz, "Simple But Accurate Equations for Wellbore Pressure Drawdown Calculation" SPE, 38314-MS 1997.

[12] L.B. Ouyang, S. Arbabi, and K. A. Aziz "Single phase wellboreflow model for horizontal vertical and slanted wells", SPE Journal, vol. 4, no. 4, pp. 124-133, 1998.

[13] L.B. Ouyang, and K. Aziz, "A General Single-Phase Wellbore/Reservoir Coupling Model for Multilateral Wells", SPE Reservoir Evaluation \& Engineering, vol. 4, no. 4, pp. 327-335, 2001.

[14] A.C. Gringarten, and H.J. Ramey Jr., "The use of source and green's functions in solving unsteady-flow problems in reservoirs", SPE, 3818-PA, pp. 285-296,1973.

[15] G. Zhao, and L. G. Thompson, "Modeling of complex geometry reservoirs", SPE, 63280-MS, 2000.

[16] H. Stehfest, "Algorithm 368 numerical inversion of Laplace transforms", Communications of ACM, vol. 13, no. 1, pp. 47-49, 1970.

[17] S. Xu "Numerical analysis and algorithms", Machinery Industry Press, no. 8, pp. 54-56, 2003.

Received: December 15,2014

Revised: January 04, 2015

Accepted: February 25, 2015

(C) Hong et al.; Licensee Bentham Open.

This is an open access articles licensed under the terms of the Creative Commons Attribution-Non-Commercial 4.0 International Public License (CC BY-NC 4.0) (https://creativecommons.org/licenses/by-nc/4.0/legalcode), which permits unrestricted, non-commercial use, distribution and reproduction in any medium, provided that the work is properly cited. 